\title{
EGFR-TKI and lung adenocarcinoma with CNS relapse: interest of molecular follow-up
}

\author{
A-M. Ruppert*, M. Beau-Faller", A. Neuvilleø, E. Guerin", A-C. Voegeli", \\ B. Mennecier*, M. Legrain\# ${ }^{\#}$ A. Molard*, M-Y. Jeung ${ }^{+}$, M-P. Gaub\#, \\ P. Oudet ${ }^{\#}$ and E. Quoix*
}

ABSTRACT: The epidermal growth factor receptor tyrosine kinase inhibitor (EGFR-TKI) erlotinib improves survival of lung cancer as second- or third-line therapy. However, after an initial response, most patients will recur, particularly within the central nervous system.

The present study reports the case of a 27 -yr-old nonsmoking male presenting with a metastatic lung adenocarcinoma with EGFR exon 19 deletion, associated with sensitivity to EGFR-TKI. Gefitinib, followed by chemotherapy and finally erlotinib resulted in prolonged disease control, until multiple liver metastases were detected. After stopping EGFR-TKI, brain metastases with carcinomatous meningitis were diagnosed. A secondary T790M mutation, associated with resistance to EGFR-TKI, was found on the liver biopsy but not in the cerebrospinal fluid. Erlotinib was reintroduced and allowed a quick neurological improvement, even though the extracranial disease remained resistant to erlotinib.

The present report underscores the interest of molecular monitoring in lung cancer. Persistent cerebral tyrosine kinase inhibitor sensitivity should be considered in patients presenting with an early central nervous system relapse after stopping epidermal growth factor receptor tyrosine kinase inhibitor, even with a T790M-resistant mutation in noncerebral metastases. Questions remain concerning the selection of sub-clones during epidermal growth factor receptor tyrosine kinase inhibitor therapy, which could differ according to metastatic sites, especially in the central nervous system.

KEYWORDS: Brain metastases, epidermal growth factor receptor, epidermal growth factor receptor tyrosine kinase inhibitor, lung cancer, mutation

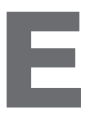
rlotinib (or gefitinib) is an epidermal growth factor receptor tyrosine kinase inhibitor (EGFR-TKI). As second- or thirdline therapy, erlotinib has demonstrated a significant survival benefit for the whole lung cancer population, including male smokers or those with squamous cell carcinoma [1]. Subgroup analyses revealed that responsiveness to EGFRTKI is more frequently observed in female nonsmokers with adenocarcinoma and is associated with specific gain of function mutations at exon 18, 19 and 21 of the EGFR gene. Those mutations are found in $10 \%$ of nonsmall cell lung cancer (NSCLC) in Europe and the USA, and in $26 \%$ of NSCLC in East Asia [2-6]. Whether the EGFR-TKIs should be prescribed as first-line treatment in a selected population remains controversial. In a recent phase II trial with erlotinib as first-line treatment in patients with
EGFR mutation, an overall response rate of $82 \%$ was observed [7].

Despite an initial response, most patients present a recurrence of the disease. Two kinds of EGFR-TKIresistant mutations have been identified. KRAS mutations are associated with primary resistance to EGFR-TKI, whereas T790M mutation is associated with secondary resistance to EGFR-TKI [810]. Recently, MET amplification has been recognised as another mechanism of EGFR-TKI resislung adenocarcinoma treated by EGFR-TKI therapy, resulting in a dissociated molecular evolution with a T790M mutation in the liver but not in the central nervous system (CNS).

\section{CASE REPORT}

A 27-yr-old nonsmoking male was referred to the Hôpitaux Universitaires de Strasbourg (France) tance [11]. The present study reports a case of a

\section{AFFILIATIONS}

Depts of ${ }^{*}$ Chest Diseases,

${ }^{*}$ Biochemistry and Molecular Biology,

-Anatomopathology, and

+Radiology, Hôpitaux Universitaires,

Strasbourg, France.

CORRESPONDENCE

E. Quoix

Dept of Chest Diseases

Hôpitaux Universitaires Strasbourg

1 place de l'Hôpital

BP 426

67091 Strasbourg

France

Fax: 33388116351

E-mail: elisabeth.quoix@chru-

strasbourg.fr

Received:

December 032007

Accepted after revision:

June 122008

SUPPORT STATEMENT

The present study was supported by the Ligue Nationale Contre le Cancer (Haut-Rhin Comity, Mulhouse,

France) and the Cancéropôle Grand Est (Strasbourg, France).

STATEMENT OF INTEREST

Statements of interest for A-M.

Ruppert, M. Beau-Faller, B.

Mennecier, A. Molard and E. Quoix can be found at

www.erj.ersjournals.com/misc/ statements.shtml 

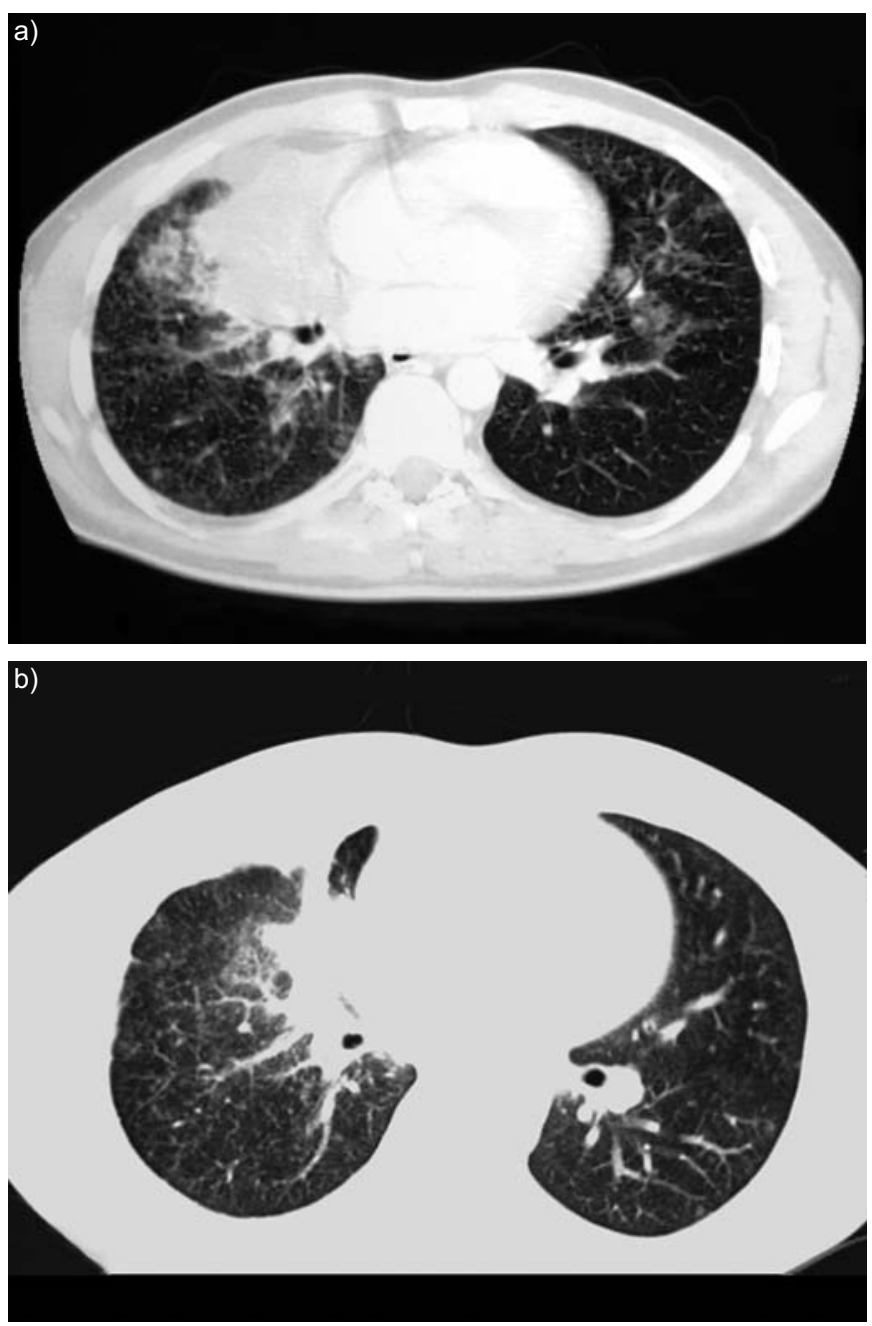

FIGURE 1. Computed tomography scans a) at diagnosis and b) after 10 months of gefitinib. a) Alveolar infiltration of the right middle lobe was seen and diffuse micronodular pattern in both lungs. b) After 10 months of genfitinib, a partial response of the alveolar infiltration of the right middle lobe was seen.

in September 2004 for cough and dyspnoea. Computed tomography (CT) scan showed an alveolar infiltration of the right middle lobe and micronodular pattern in both lungs (fig. 1a). Bronchoalveolar lavage revealed a non-mucinous adenocarcinoma. Brain CT and positron emission tomography found a single metastasis at the right cotyloid notch, which was histologically proven. Thus, a stage IV (T4N2M1) adenocarcinoma of pneumonic type previously known as diffuse bronchioloalveolar carcinoma was diagnosed [12]. Retrospective sequencing analyses of the bone biopsy revealed an exon 19 deletion of EGFR, associated with sensitivity to EGFR-TKI therapy.

The patient was included in a phase II trial (IFCT 04-01) of EGFR-TKI $\left(250 \mathrm{mg} \cdot\right.$ day $^{-1}$ gefitinib (Iressa ${ }^{\circledR}$; AstraZeneca, Macclesfield, UK)). A clinical and radiological partial response, according to Response Evaluation Criteria in Solid Tumours (RECIST), was noted within 2 weeks (fig. 1b). In January 2006, the patient had a thoracic and cerebral relapse treated with chemotherapy (six courses of carboplatine (area under curve
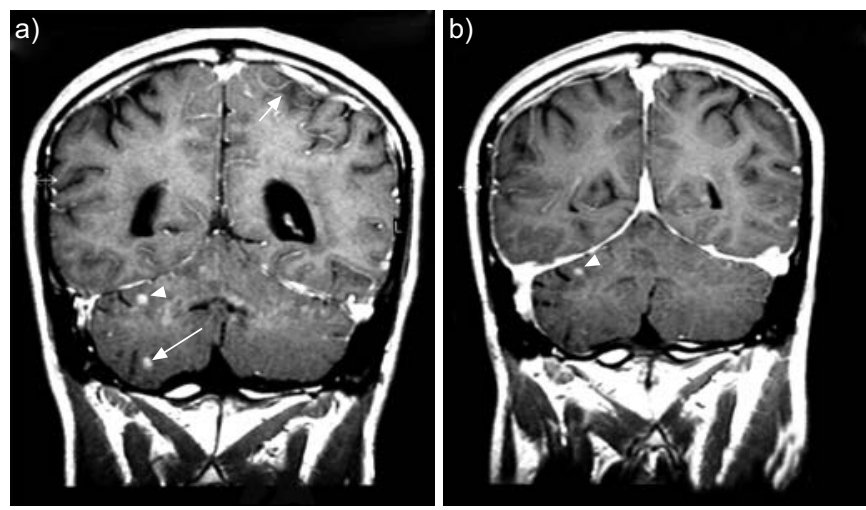

FIGURE 2. a) Brain magnetic resonance imaging (MRI; T1 with gadolinium) Multiple brain metastases (arrowhead) with an intensive signal of the leptomeninges marking carcinomatous meningitis (arrow). b) Brain MRI (T1 with gadolinium) after 1 month of erlotinib. Partial response of the brain metastases (arrowhead) and disappearance of the intensive signal of the leptomeninges.

(AUC) 6)-paclitaxel $\left(175 \mathrm{mg} \cdot \mathrm{m}^{2}\right)$; day $1=$ day 22$)$ associated with brain irradiation (30 Gy). At 1 month after stopping chemotherapy, a pulmonary relapse occurred and retreatment with EGFR-TKI (150 mg·day ${ }^{-1}$ erlotinib (Tarceva ${ }^{\circledR}$; Roche, Basel, Switzerland)) was carried out until January 2007, when multiple liver metastases were detected. A secondary T790M resistance mutation in exon 20 of EGFR was found on the liver biopsy. Erlotinib was stopped and chemotherapy (cisplatine $\left(80 \mathrm{mg} \cdot \mathrm{m}^{2}\right.$; day $1=$ day 22$)$-vinorelbine $\left(25 \mathrm{mg} \cdot \mathrm{m}^{2} ;\right.$ day $1=$ day 8 ) one course, followed by pemetrexed $\left(500 \mathrm{mg} \cdot \mathrm{m}^{2}\right.$; day $1=$ day 22) six courses) commenced. At the end of March 2007, the patient complained of headaches and hypoacousia, revealing cerebral metastases (fig. 2a) with cytological proven carcinomatous meningitis. A total of 13 bi-weekly intrathecal methotrexate $(15 \mathrm{mg})$ injections were administrated without effect. Mutational analyses in the cerebrospinal fluid (CSF) showed the exon 19 deletion without the T790M resistance mutation. Thus, in May 2007, erlotinib (150 mg.day $\left.{ }^{-1}\right)$ was reintroduced. A clinical neurological improvement was noted within a week, with a partial response shown upon cerebral magnetic resonance imaging (fig. $2 b$ ) and the disappearance of

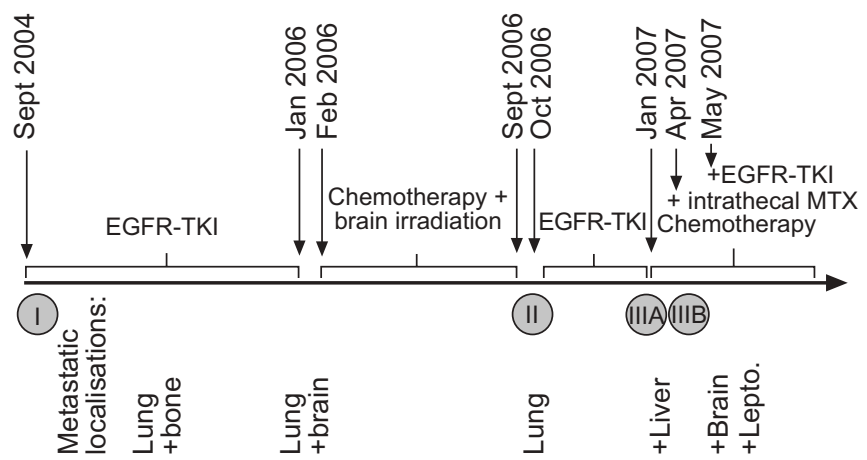

FIGURE 3. Chronology of disease progression, treatments and different tumour specimens. Tumour specimens analysed were as follows. Sample I: bone biopsy; sample II: bronchial biopsy; sample IIIA: hepatic biopsy; sample IIIB: cerebrospinal fluid. EGFR-TKI: epidermal growth factor receptor tyrosine kinase inhibitor; MTX: methotrexate; lepto.: leptomeninges. 


\begin{tabular}{|c|c|c|c|c|c|c|c|}
\hline Sample & Clinical characteristics & \multicolumn{2}{|c|}{ SQS } & \multicolumn{2}{|c|}{ QPCR } & \multicolumn{2}{|c|}{$\mathrm{IHC}$} \\
\hline I & Initial: bone biopsy & L747_P753,insQ & Wild-type & $3.08(0.95)$ & $0.29(0.22)$ & 200 & 0 \\
\hline II & $\begin{array}{l}\text { First relapse: bronchial } \\
\text { biopsy }\end{array}$ & L747_P753,insQ & Wild-type & $2.50(0.80)$ & $0.33(0.03)$ & 200 & 0 \\
\hline IIIA & $\begin{array}{c}\text { Second relapse: liver } \\
\text { biopsy }\end{array}$ & L747_P753,insQ T790M & Wild-type & $6.6(0.82)$ & $0.91(0.12)$ & 360 & 100 \\
\hline IIIB & $\begin{array}{l}\text { Second relapse: cere- } \\
\text { brospinal fluid }\end{array}$ & L747_P753,insQ & Wild-type & $2.65(0.7)$ & $1.10(0.10)$ & & \\
\hline
\end{tabular}

Data are presented as DNA copy number (SD), unless otherwise stated. Immunochemistry (IHC) for protein expression of epidermal growth factor receptor (EGFR) and MET were assessed using a semi-quantitative approach to generate a score from 0-400, as previously described [6]. SQS: sequencing status; QPCR: quantitative realtime PCR.

tumour cells in the CSF. Erlotinib and chemotherapy for the extra-cranial disease are therefore ongoing. The successive treatments are summarised in figure 3.

\section{MATERIALS AND METHODS}

Four tumour specimens from the patient were analysed: one obtained at diagnosis (bone metastasis: sample I); one at the first relapse under EGFR-TKI therapy (bronchial biopsy: sample II); and two at the second relapse under EGFR-TKI therapy (liver metastasis: sample IIIA; and CSF: sample IIIB). Consent for the use of the samples to perform investigational studies was obtained from the patient.

a)

a) $G$ G A A W A A RA G
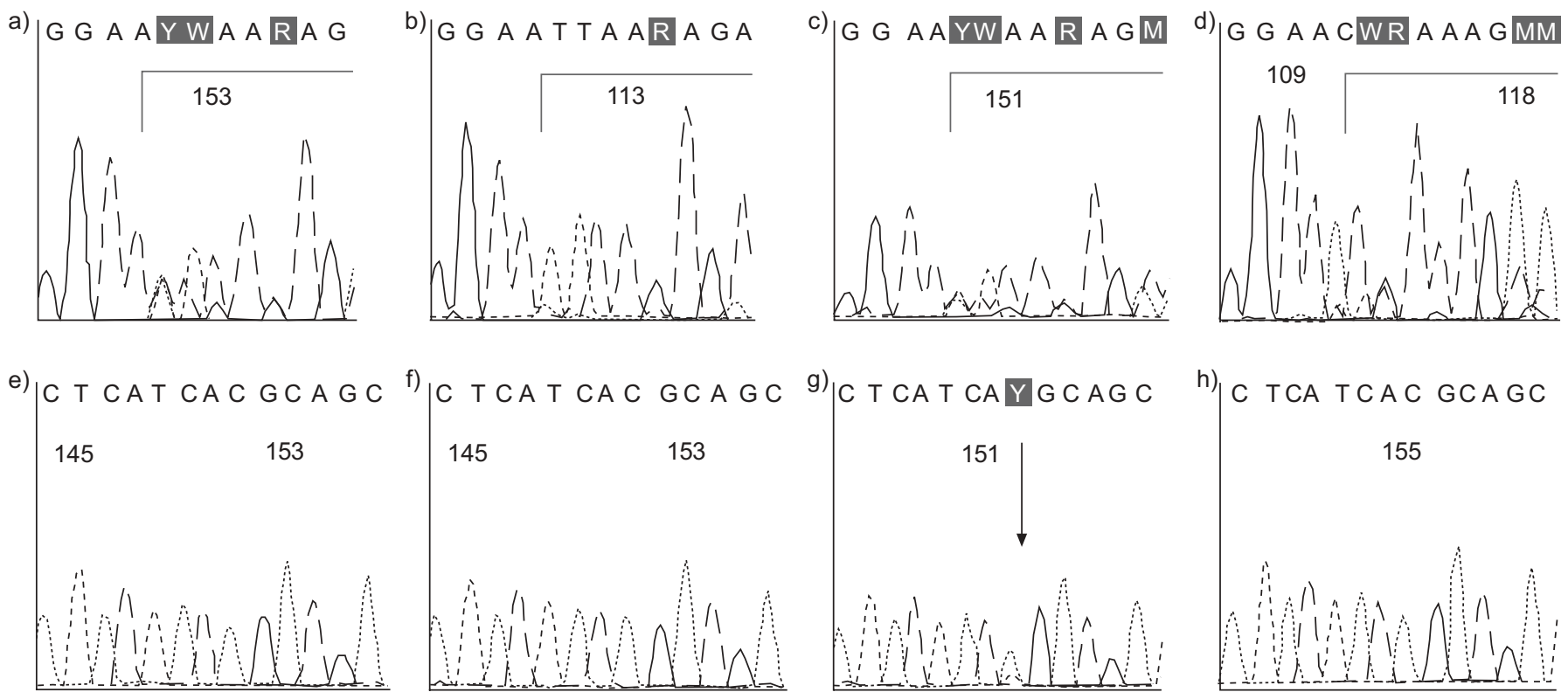

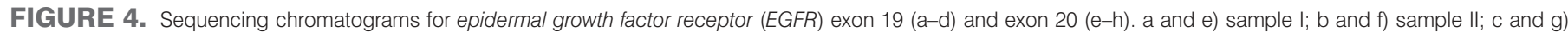

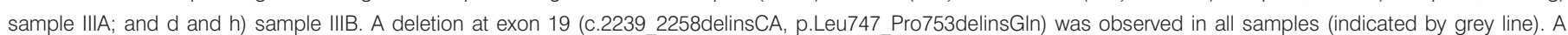

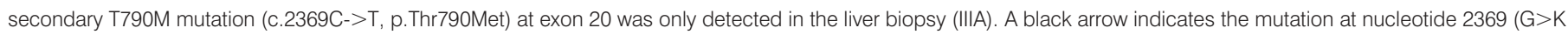

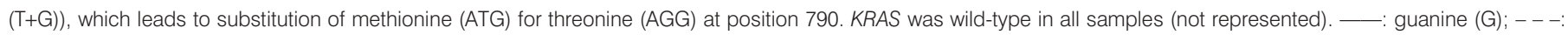
adenine $(A) ;---$ : thymine $(T) ; \cdots \cdots \cdots . .$. cytosine $(C)$. 
Real-time quantitative PCR for EGFR and MET was determined using the LightCycler 2.0 system (Roche Diagnostics, Mannheim, Germany) and the LightCycler FastStart DNA Master SYBR Green Kit (Roche Diagnostics). The standard curve method was used to calculate targeted gene copy number, normalised to a normal reference DNA. Quantification was based on a standard curve from a serial dilution of normal human genomic DNA. All specimens were analysed in duplicate. Two reference genes were used for each targeted gene ( $\beta$-globine and COG-5 for EGFR; $\beta$ globine and GADPH for MET). The EGFR PCR primers are previously described at exon/intron 19 of EGFR [5]. The MET PCR primers are directed at exon 15/intron 15 of MET and are available on request.

Protein expression was assessed using immunochemistry for EGFR (clone 3C6, Ventana Medical Systems Inc., Tucson, AZ, USA) and for MET (polyclonal antibody C-28, Santa Cruz Biotechnology Inc., Santa Cruz, CA, USA) with a semiquantitative approach [6].

\section{RESULTS}

The results of the present study are summarised in table 1 . The cotyloid tumour sample (sample I) displayed a deletion at exon 19 of EGFR (c.2239_2258delinsCA, p.Leu747_Pro753delinsGln). This mutation was found in all of the samples (fig. 4). A secondary mutation in exon 20, leading to a substitution of methionine for threonine at position 790 (c.2369C->T, p.Thr790Met) is found on the liver biopsy (sample IIIA), but not in the CSF (sample IIIB; fig. 4). There was no mutation of KRAS in all the samples. DNA status of EGFR and MET was simultaneously available by quantitative real-time PCR. EGFR copy number is high in all the samples with the highest amplification in sample IIIA. A deletion of MET was observed in samples I and IIA, and a normal copy number in samples III (A and B). An overexpression of EGFR protein was observed in all the samples with the highest amplification in the liver metastasis (sample IIIA). MET protein was expressed in the sample IIIA and was lacking in the previous samples (I and II).

\section{DISCUSSION}

EGFR played a predominant role in the current patient's oncogenesis. Sequencing analyses of the biopsy at diagnosis showed wild-type KRAS and an exon 19 deletion of EGFR, associated with sensitivity to EGFR-TKI. Despite an initial response under TKI, disease recurred with a secondary T790M resistance mutation of EGFR. No MET amplification was detected. The high incidence of disease relapse in the CNS after initial response to EGFR-TKI is striking [13]. In contrast to the novel D761Y EGFR mutation, the T790M is associated with multiple metastatic sites, except the CNS, as previously confirmed $[14,15]$. This finding implies that selection pressure in the CNS could be different from that in the rest of the body. Incomplete CNS penetration of the EGFR-TKI has previously been reported $[15,16]$. The CSF penetration of erlotinib, based on the respective CSF and plasma AUC (0-24 h) attains a ratio of $6.9 \%$ [16]. Whether the low CSF drug level is adequate enough to inhibit tumour growth remains controversial [15, 16]. The lack of the EGFR resistance mutation in the CSF led the present authors to re-treat the patient with erlotinib $\left(150 \mathrm{mg} \cdot\right.$ day $\left.^{-1}\right)$, which allowed neurological improvement within a week, even though the extra-cranial disease remained resistant to erlotinib. Interestingly, no increased dose of EGFRTKI was necessary to obtain a clinical response on the CNS metastases, which is in contrast with a recent case report [15].

It is still not known how tumour cells bearing the T790M mutation arise under EGFR-TKI. Treatment by EGFR-TKI selects the resistant clones because the sensitive cells die. Thus, T790M is displayed only in sample IIIA, and MET is deleted in samples I and II, with normal copy number in samples IIIA and IIIB (table 1). Heterogeneity among the different tumour samples is confirmed by allelotyping, with a different pattern for 48 analysed microsatellites (data not shown).

Sequencing as currently used has technical limitations in its ability to detect mutations. Novel sensitive methods are under investigation with regard to detecting sub-clones bearing the T790M mutation at an infraclinical level, which may affect tumour response or time to progression under EGFR-TKI.

The present report underscores the interest of molecular monitoring of lung cancer. Persistent cerebral tyrosine kinase inhibitor sensitivity should be considered in patients presenting with a central nervous system relapse after stopping epidermal growth factor receptor tyrosine kinase inhibitor, even with a T790M resistant mutation in noncerebral metastases. Questions remain concerning the selection of sub-clones during epidermal growth factor receptor tyrosine kinase inhibitor therapy, which could differ according to metastatic sites, especially the central nervous system.

\section{REFERENCES}

1 Shepherd FA, Rodrigues Pereira J, Ciuleanu T, et al. Erlotinib in previously treated non-small-cell lung cancer. N Engl J Med 2005; 353: 123-132.

2 Paez JG, Janne PA, Lee JC, et al. EGFR mutations in lung cancer: correlation with clinical response to gefitinib therapy. Science 2004; 304: 1497-1500.

3 Lynch TJ, Bell DW, Sordella R, et al. Activating mutations in the epidermal growth factor receptor underlying responsiveness of non-small-cell lung cancer to gefitinib. N Engl J Med 2004; 350: 2129-2139.

4 Shigematsu H, Lin L, Takahashi $\mathrm{T}$, et al. Clinical and biological features associated with epidermal growth factor receptor gene mutations in lung cancers. J Natl Cancer Inst 2005; 97: 339-346.

5 Bell DW, Lynch TJ, Haserlat SM, et al. Epidermal growth factor receptor mutations and gene amplification in nonsmall-cell lung cancer: molecular analysis of the IDEAL/ INTACT gefitinib trials. J Clin Oncol 2005; 23: 8081-8092.

6 Hirsch FR, Varella-Garcia M, Bunn PA Jr, et al. Epidermal growth factor receptor in non-small-cell lung carcinomas: correlation between gene copy number and protein expression and impact on prognosis. J Clin Oncol 2003; 21: 3798-3807.

7 Paz-Ares L, Sanchez LM, Garcia-Velasco A, et al. A prospective phase II trial of erlotinib in advanced nonsmall cell lung cancer patients with mutations in the tyrosine linase domain of the epidermal growth factor receptor. ASCO Meeting Abstracts 2006; 24: 7020. 
8 Pao W, Wang TY, Riely GJ, et al. KRAS mutations and primary resistance of lung adenocarcinomas to gefitinib or erlotinib. PLoS Med 2005; 2: e17.

9 Pao W, Miller VA, Politi KA, et al. Acquired resistance of lung adenocarcinomas to gefitinib or erlotinib is associated with a second mutation in the EGFR kinase domain. PLoS Med 2005; 2: e73.

10 Kobayashi S, Boggon TJ, Dayaram T, et al. EGFR mutation and resistance of non-small-cell lung cancer to gefitinib. $N$ Engl J Med 2005; 352: 786-792.

11 Engelman JA, Zejnullahu K, Mitsudomi T, et al. MET amplification leads to gefitinib resistance in lung cancer by activating ERBB3 signaling. Science 2007; 316: 1039-1043.

12 Wislez M, Massiani MA, Milleron B, et al. Clinical characteristics of pneumonic-type adenocarcinoma of the lung. Chest 2003; 123: 1868-1877.
13 Omuro AM, Kris MG, Miller VA, et al. High incidence of disease recurrence in the brain and leptomeninges in patients with nonsmall cell lung carcinoma after response to gefitinib. Cancer 2005; 103: 2344-2348.

14 Balak MN, Gong Y, Riely GJ, et al. Novel D761Y and common secondary T790M mutations in epidermal growth factor receptor-mutant lung adenocarcinomas with acquired resistance to kinase inhibitors. Clin Cancer Res 2006; 12: 6494-6501.

15 Jackman DM, Holmes AJ, Lindeman N, et al. Response and resistance in a non-small-cell lung cancer patient with an epidermal growth factor receptor mutation and leptomeningeal metastases treated with high-dose gefitinib. J Clin Oncol 2006; 24: 4517-4520.

16 Broniscer A, Panetta JC, O'Shaughnessy M, et al. Plasma and cerebrospinal fluid pharmacokinetics of erlotinib and its active metabolite OSI-420. Clin Cancer Res 2007; 13: 1511-1515. 